\title{
FORUM
}

\section{The Calvert Methods of Manœuvring to Avoid Collision at Sea and of Radar Display}

\author{
from Captain F. J. Wylie, R.N.
}

THESE methods were briefly described in the Journal (Vol. I 3, No. 2). They were prefaced by some comments designed to draw a comparison between the air and sea problems and collision rates. Statistics are liable to be misleading if not perfectly understood and definitive, and marine collision statistics as much as any. It should be realized that Lloyd's List figures include almost every collision incident to ships of 500 tons and over and that a comparable air figure would probably need to include damage to aircraft by aircraft on airfields and in hangars and whether under their own power or in tow.

Again, in comparing the numbers of collisions in successive years, it should be remembered that we are considering a period in which the total number of ships increased some 20 per cent in 10 years. It would certainly be unwise to draw conclusions from such general figures, while those embodying the important factors of relevance are almost impossible to gather.

When considering the efficacy of the present Rule of the Road at sea, it will be realized that in clear weather and straightforward situations collisions hardly ever occur. When they do happen, there are usually extraneous or confusing circumstances which would affect adversely any system or rule of thumb.

It is not clear from Mr. Calvert's paper that he is aware that Rules 17 to 24 can only be applied when the ships can see one another visually. In fog there are no give-way nor stand-on ships.

Another comparison made deserves comment; that the mariner has ten times as long as the airman to make up his mind needs to be followed up with-ten times longer to move a ship out of the way and ten times longer to see whether the manouvre is proving effective.

To pass to the main questions involved, this comment will only refer to the fog condition and to the sea; it falls into two distinct parts, on the proposed mancuvres and on the special type of display.

Concerning the manouvres, several suggestions have been made in the past which, though not identical with Mr. Calvert's, have been based on the idea of a set manœuvre in which the direction and sometimes the amount of the change have been specified. All these have failed to attract support for one or more of the following reasons.

For any such scheme to be effective, it must have universal application, except in those inland waters which have special rules, it must be quite independent of sea-room, it must work as well in crowded waters as for two ships in mid-ocean and it must demand no bilateral planning and cooperation, such as would require positive identification of the radar echo with a particular voice communication by radio.

The circumstances of encounters at sea in fog do not admit of the master having to wait for a clear radio channel, to interpret a foreign language or to 
decide whether he is being faced with intelligent cooperation, plain stupidity or complete inertia.

Mr. Calvert's system is, as he says, a simple one connecting the evasive manœuvre with the sector in azimuth from which the threat comes. He does not insist that both craft should mancuvre but points the advantage of so doing. Also he admits that a reversal of the manœuvre may be the more effective and is permissible but insists that, in that case, a signal must be exchanged between the ships concerned.

It is quite possible at sea that one threat will come from a direction which demands a starboard turn and, needing simultaneous consideration, another which demands a port turn. By Mr. Calvert's thesis, both cannot be satisfied unambiguously by the same mancuvre without a communication being passed to one of them. It may be argued that they could usually be dealt with separately but this is not a safe generalization. A ship closing at 30 knots from Io miles fine on the bow may demand more urgent action than one only 5 miles on the beam. The latter, however, may have other views on priorities but there is no-one to allocate them and no-one to dispose of doubts and misinterpretations. The open sea cannot be treated as an airfield approach. Further, ships A and B, performing set mancuvres for the avoidance of ships $X$ and $Y$ respectively, may find mutual danger in this limiting of their discretion.

Although, in a two-ship situation, he does not insist on both ships mancuvring, it is obviously important that the other should not do anything in the reverse sense. No reliance could be placed on this hope, particularly in crowded waters, and it is always wise to remember that not all changes of course and speed are related to collision avoidance. Even in fog ships must try to advance towards their destinations.

Two of the manouvres suggest an increase of speed and in one of them it is obligatory. It is also suggested that speed in open waters need only be reduced enough to allow a ship to 'put on a small burst of speed' when required. It is doubtful that this will find favour among those responsible for improving the conditions for safety at sea, while it might have unnerving consequences in multi-lateral situations. It should be added that big tankers and cargo ships take a long time to gain or lose speed.

No doubt Mr. Calvert is mathematically correct in his statement that half the approach time may be spent in observation before manœuvring but this does not seem to take into account that a minimum pass distance of two or three miles may be desired as well as minimum divergence from the desired route. Neither does it give sufficient scope for making intentions clear as early as practicable and for discerning and remedying the simultaneous and mutually destructive mancuvre. Only a few of the imponderables of seafaring in fog have been mentioned here but even these may suggest that more than geometry and a rule of thumb is needed to ensure safety.

With regard to the display, comment is more difficult because only a very brief description is available. It has been ascertained that the 'index' of own ship is in fact the centre of the scan, which is made to move away from the centre of the PPI when the special 'drives' are introduced. The motion of the index is then the vector sum of the present true motion of own ship and the original motion. Similarly the motion of an echo is then the vector sum of the other ship's present motion and own ship's original motion:

In view of the unlikelihood of any form of set manœuvre or rule of thumb 
being found to offer a solution to the maritime problem, what $\mathrm{Mr}$. Calvert refers to as the overriding advantage of his display may be disregarded. The other main advantage claimed is the way in which an alteration by another vessel is immediately apparent whether or not own ship has altered.

To examine this claim it may be useful to compare, in each phase of a situation involving alterations by each of two ships, the assistance given by the Calvert display with that afforded by the orthodox relative and true-motion varieties. This comparison is shown in the table, in which four items of information are examined before, during and after an alteration by own ship.

Although it is not certain that $\mathrm{Mr}$. Calvert advocates a reflection plotter, it has been assumed that one is available with each type of display because this permits a fairer comparison. Three symbols are employed in the table to denote different phases of plotting, $A, B$ and $C$ indicating increasing degrees of complexity. Thus :

A. Direct plotting of echo and own ship tracks with no construction other than the marking of times at appropriate intervals.

$B$. Construction of velocity triangle on $A$.

$C$. On Calvert display only, where a double construction is necessary if target new course and speed are required. The first stage is as in $B$, to find relative track, and the second to apply own true course and speed to the relative track to find target's true motion.

Some further explanation may be necessary of the symbol $A / B$ seen at one point of the table. This is used because the C.P.A. information may be wanted in either of two forms. If the C.P.A. is needed in relation to the latest courses and speeds of the two ships, it is necessary to have plotted the Calvert tracks (A plot), to construct on the target's echo track the velocity triangle for the two 'Calvert' courses and speeds and so obtain the relative track, a $B$ plot; this incidentally is the same track as would be obtained by computing the true courses and speeds. The distance measured at right angles from this track to the appropriate point on own ship's track gives the C.P.A. required (Fig. I).

On the other hand, if it is desired to know what would be the C.P.A. if own ship resumed her original course and speed at a given point ahead, it is only necessary to measure from this point to the other ship's echo track, at right angles to the latter or its extension; this is an $A$ plot (Fig. 2). It will be appreciated that it is easier to plot than to describe the process!

A brief study of the table will show that before own ship alters, the true motion display has the advantage of both Calvert and the relative display except when C.P.A. information is required; however, changing temporarily to relative motion gives equality in this respect. The words in situ in the note to the table are to suggest that the true motion display is 'stopped' for this purpose but not re-centred.

During own ship's alteration, the true motion display has great advantage over the relative and only slightly less over Calvert. In this period Calvert has the distinct advantage over the relative that the occurrence, though not the detail, of an alteration by the other vessel may be seen quickly.

After own ship's alteration, true motion still has the major advantage and, in most ways, the relative display also is preferable to Calvert.

In general the Calvert display with the drives connected provides motion to own ship which is not true motion and to echoes a motion which is neither true 


\begin{tabular}{|c|c|c|c|c|c|}
\hline \multirow[b]{2}{*}{ Period } & \multirow[b]{2}{*}{$\begin{array}{l}\text { Indication } \\
\text { required }\end{array}$} & \multicolumn{3}{|c|}{ Type of display } & \multirow[b]{2}{*}{ Remarks } \\
\hline & & $\begin{array}{l}\text { Relative: } \\
\text { compass- } \\
\text { stabilized; } \\
\text { reflection }\end{array}$ & $\begin{array}{l}\text { True- } \\
\text { motion: } \\
\text { reflection } \\
\text { plotter }\end{array}$ & $\begin{array}{c}\text { Calvert: } \\
\text { with reflec- } \\
\text { tion plot- } \\
\text { ter }\end{array}$ & \\
\hline $\begin{array}{l}\text { Before change } \\
\text { of own course } \\
\text { and/or speed }\end{array}$ & $\begin{array}{l}\text { C.P.A. } \\
\text { informn. } \\
\text { True course and } \\
\text { speed of tar- } \\
\text { get } \\
\text { Occurrence of } \\
\text { alteration by } \\
\text { target } \\
\text { Type of alter- } \\
\text { ation by tar- } \\
\text { get }\end{array}$ & $A^{*}$ & $A^{*}$ & $A^{*}$ & $\begin{array}{l}\text { Calvert display } \\
\text { is relative until } \\
\text { 'drives' are } \\
\text { connected, i.e. } \\
\text { when own ship } \\
\text { alters to avoid } \\
\text { collision. }\end{array}$ \\
\hline $\begin{array}{l}\text { During change } \\
\text { of own course } \\
\text { and/or speed }\end{array}$ & $\begin{array}{l}\text { C.P.A. } \\
\text { informn. } \\
\text { True course and } \\
\text { speed of tar- } \\
\text { get } \\
\text { Occurrence of } \\
\text { alteration by } \\
\text { target } \\
\text { Type of alter- } \\
\text { ation by tar- } \\
\text { get }\end{array}$ & NO & $\begin{array}{c}\text { NO } \\
\cdot\end{array}$ & NO & \\
\hline $\begin{array}{l}\text { After change } \\
\text { of own course } \\
\text { and/or speed } \\
\text { ('Drives' still } \\
\text { connected in } \\
\text { Calvert) }\end{array}$ & $\begin{array}{l}\text { C.P.A. } \\
\text { informn. } \\
\text { True course and } \\
\text { speed of tar- } \\
\text { get } \\
\text { Occurrence of } \\
\text { alteration by } \\
\text { target } \\
\text { Type of alter- } \\
\text { ation by tar- } \\
\text { get }\end{array}$ & $B$ & $A^{*}$ & $A / B$ & \\
\hline
\end{tabular}

* Also by echo trail if tube afterglow and range-scale are suitable.

$\dagger$ Or by switching temporarily to Relative display (in situ)

$\ddagger$ Or by transferred plot (true or relative). 

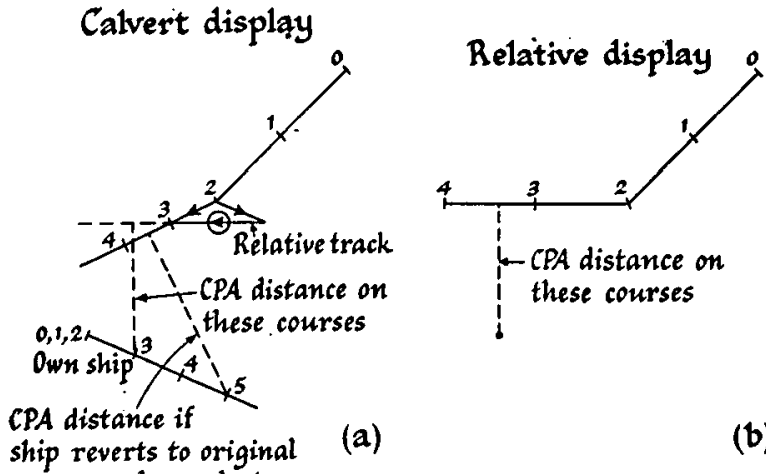

True motion display

ship reverts to original

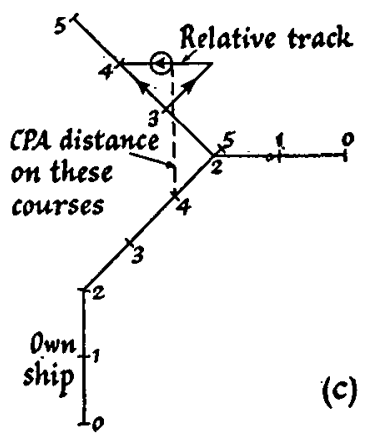

Fig. 1. Plotting the relative track.

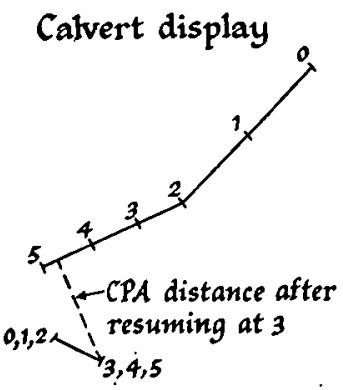

(a)

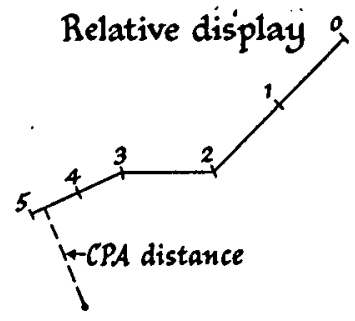

(b)
True motion display

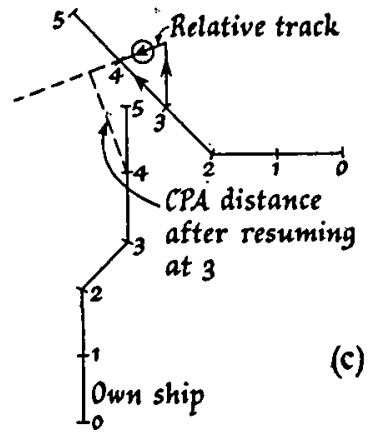

Fig. 2. Resuming original course and speed.

nor relative to own ship. The result is a presentation, which as far as prediction is concerned, has very little advantage over relative display (stabilized) and none over true motion, but has the disadvantage of often looking utterly different from the visual and normal relative pictures.

Further, although it may show the other ship holding a steady course during and after an alteration by own ship, it will not show the new C.P.A. information directly. It will show directly the C.P.A. resulting from own ship reverting to original course and speed at a given moment, but not, of course, to any other course and speed. It must be emphasized that in the maritime case quantitive information is needed. It is not enough to inform the navigator that the miss distance is increasing or decreasing. He will want to know by how much and with what effect on the rate of approach.

Although it will indicate when the other ship alters, it will not show whether it is a change of course or speed or both nor, quantitively, what is the effect on the C.P.A. In some cases easily recognizable features are lost. Two comparative examples are shown in Fig. 3.

There is an implication that this display is intended primarily to deal with a particular collision situation in isolation. At sea it is necessary to keep a number 

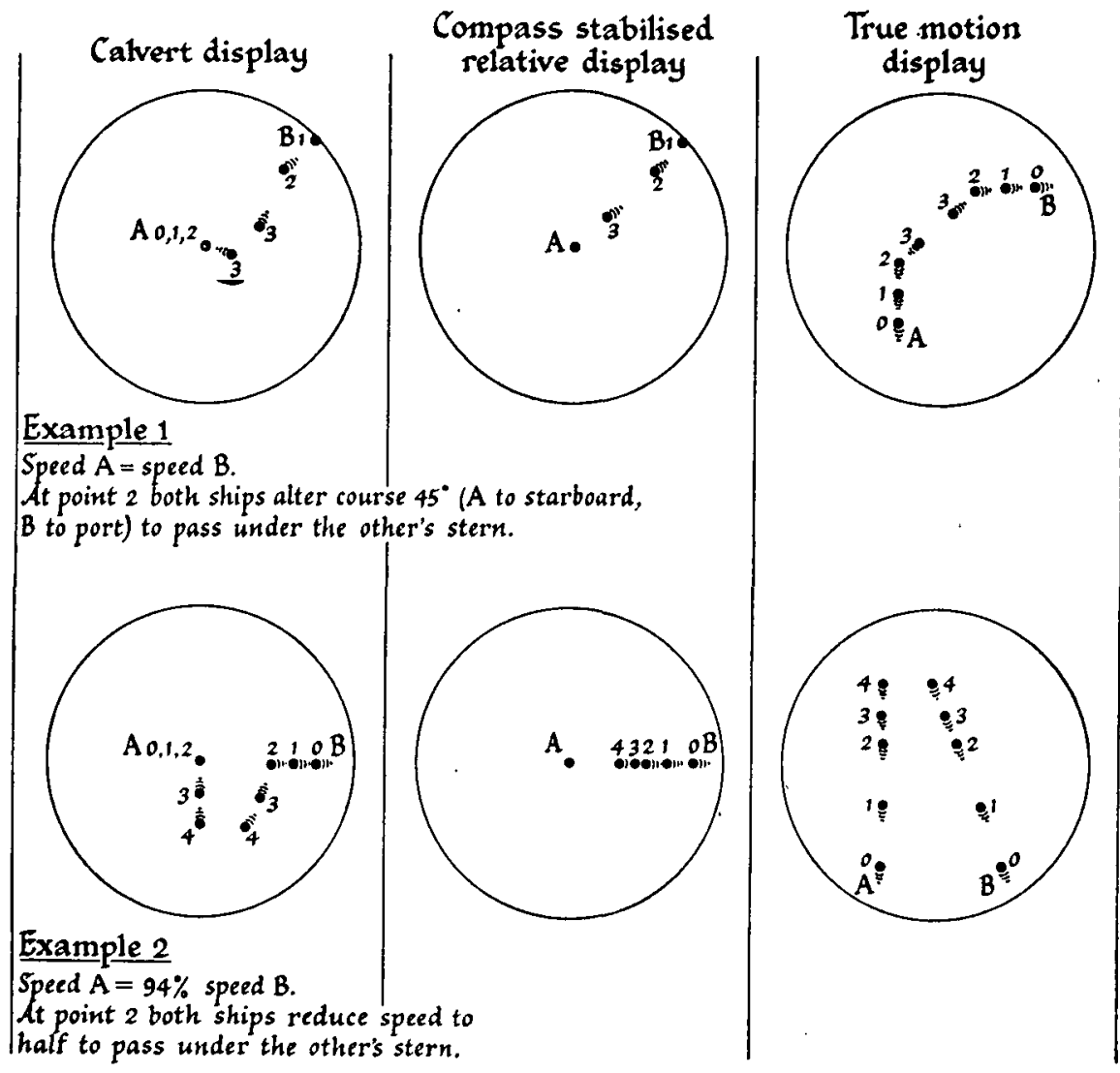

Fig. 3. Collision situations.

of potential collision situations under continuous and coherent observation, particularly when own ship has made an alteration. Further, the navigation of the ship on land fixes by radar must also be continued throughout if targets are available. Hence, it would be necessary to switch the display from 'Calvert' to relative or true motion at frequent intervals and at critical moments.

In my view the only possible conclusion is that this display would not ease the burden of the mariner nor increase safety at sea in fog.

\section{from Commandant Planty}

To remove the relative speed $V_{R}$ from the menacing position it presents in collision situations (constant bearing), the seaman modifies that factor in the triangle of velocities which is most under his control, his own speed $V_{A}$. First, the direction of $V_{A}$ may be modified: the course is altered while the speed remains steady. This is the normal procedure in clear weather. Secondly, the magnitude of $V_{A}$ may be modified-a variation in speed with no alteration of heading (in fog slowing down and stopping as another ship approaches is the only manouvre prescribed by the Regulations). Thirdly, both modifications of $V_{A}$ (in direction and magnitude) may be carried out simultaneously: a common practice in clear weather, and now advocated as the correct solution in fog by E. S. Calvert, who 
calls them the 'Standard Manœuvres'. He has drawn up an attractive scheme of procedure, but the following considerations make it difficult to share his optimistic hopes.

\section{OBJECTIONS}

I. It can be a risky business to carry out modifications of velocity simultaneously in both direction and magnitude. The triangle of velocities (Fig. I) shows that if the alteration of course is made towards the other ship B (producing a progressively decreasing relative bearing) it must be accompanied by a reduction in speed. If speed is increased there is a danger that a particular value for the new relative speed may again produce a position in which the bearing is steady.

The point at the end of the relative speed $V_{R}$, instead of describing a curve $\left(C_{1}\right)$ inside the circle with centre $V_{B}$ and radius $V_{A}$ (i.e. the circle which would be described if the speed $V_{A}$ remained constant in length), will describe a curve $C_{2}$ outside that circle.

If the increase in speed is equal to $\triangle V_{A}$, then this curve becomes the straight line BA, and the bearing remains steady.

It is true that $\triangle V_{A}$, which becomes infinite when the alteration of course coincides with

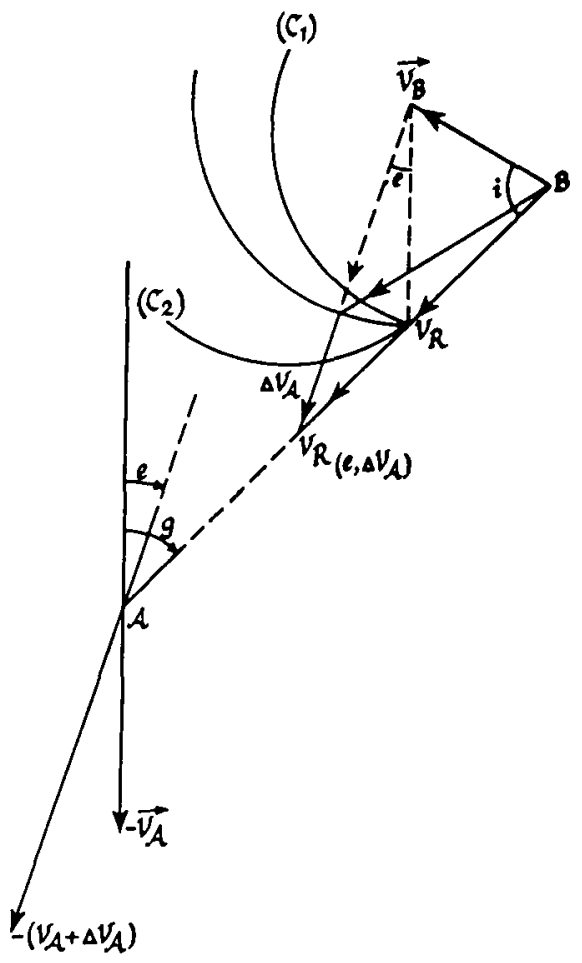

Fig. 1. Modification of the speed triangle.

B's original bearing, increases very rapidly, and $\Delta V_{A}$ reaches theoretical values far greater than those found in practice in merchant ships. Nevertheless such a situation can arise when a ship has been travelling much below its normal cruising speed.

Similarly it can be seen that if the alteration of course is made away from the other ship (on an increasing relative bearing) it must be accompanied by an increase in speed: and with ordinary merchant ships this is possible only when a ship has already been travelling at reduced speed. Further, if we remember that any mancuvre is bound to check a ship's speed, it will reinforce our contention that any alteration of course which produces a progressively increasing bearing must be accompanied by an increase in speed.

There appear to be some cases where the manœuvre advocated by Calvert violates these conclusions: in particular case 4 (where speed is reduced while A's alteration of course is tending to increase the bearing of $B$ ), and case 6 (where speed is increased while the alteration is tending to decrease the bearing).

2. The area of manouvre is divided into too many sectors: as a result there is a 
corresponding increase in the difficulty of determining the limits of each sector, and of the risk of an inappropriate mancuvre being adopted through a false estimate of one's own sector. That this risk is far from trifling is shown by the fate of the Listrac which turned on the appreciation (in clear weather) of the value of two points abaft the beam, and by the fact that, according to Calvert, the loss of the Andrea Doria was also due to a false estimate of bearing.

In the cases described by Calvert an inappropriate manœuvre in sector $70^{\circ} / 80^{\circ}$ or $25^{\circ} / 260^{\circ}$, or again in $290^{\circ} / 300^{\circ}$, can be a source of danger. It would be highly advisable to reduce these sectors in number.

3. Simultaneous mancurre by both ships. It is well known that during any manœurre the situation is largely beyond the control of the man on the bridge so long as the mancuvre is in progress; and when two ships are manœuvring simultaneously it is completely out of his control. Simultaneous mancuvre, then, is fraught with danger. The Steering and Sailing Rules make no allowance for it in clear weather (except in cases when the bearing is $0^{\circ}$, and then with extreme caution), and yet in clear weather the conditions for an accurate appreciation are at their most favourable. It seems most unwise to allow it as a general principle in fog, the more so that there is no special provision for ships not equipped with radar.

To get round these difficulties the author proposes the use of a special display which enables an observer to follow on the radar screen his own ship's changing relation to its original position (heading and speed): an interesting and potentially valuable device which gives a concrete picture of what the ship has done. There is a danger, however, that these new echoes may complicate observation of the screen, particularly when several other vessels are within range. Moreover, as we shall soon see, it does not really give the master the answer he wants. There is no doubt that disengagement can be successful when only one of the two ships takes avoiding action-why then not make it clear which ship should give way to the other? Otherwise we get what happens on a pavement when two pedestrians try to avoid one another and only succeed in colliding.

To sum up, and without denying the correct geometric bases of manœuvres 4 and 6, on the whole the author's 'Standard Mancuvres' seem to be at once difficult, and even dangerous, to apply because of the large number of sectors of mancuvre, and confusing by leaving the initiative in manœuvre to the commonsense and energy of one party without specifying which.

The root of the problem. The seaman's difficulty is to know not what he himself, but what the other man is going to do. No difficulty arises if you can be sure that he will maintain his course and speed. The captain of the Andrea Doria assumed that the Stockholm would hold her course, and took what he thought to be appropriate action. It never occurred to the Stockholm's officer of the watch that the Andrea Doria might alter to port, and he automatically took the rule-book action for clear weather of altering to starboard. They both based their decision on what they assumed would be the other's reaction; and it is just in that assumption that the danger lies, for the other ship's reaction is covered by no rule. Only Rules of Priority can control it.

If we can establish such rules, if, that is, we can lay down general rules to determine which ship must give way to the other, we shall have gone a long way towards solving our problem.

With this aim in view, we have published in the July number of Navigation (Paris) an article entitled Radar and Priority which investigates the possibility of 
applying a simple and rapid interpretation of the Steering and Sailing Rules to the radar screen. Without anticipating what is said there, the following is the gist of what lies behind the title:

Radar and Priority. The Sailing and Steering Rules determine priority from two aspects :

(1) The bearing on which the other ship is observed.

(2) The angle which the observer's ship presents to the other ship.

In the particular case where there is a risk of collision, that is to say when the relative speed passes by the observer, this second angle is, in the triangle of velocities, the aspect of the other ship. According as the aspect is smaller or greater than two points abaft the beam the ship is said to be crossing or overtaking. And this, combined with the bearing, determines which of the two ships has priority. Bearing is read off easily enough on the radar screen. Aspect is a more difficult matter. In the triangle of velocities we have the expression (Fig. 2):

$$
V_{R}=\frac{V_{N}}{\sin I} \sin (g+1)
$$

which gives the aspect of $B$ as a function of the known speed of the observer, of the bearing, and of the relative speed: all measured by the observer on the screen (by the movement of the echo on the steady bearing).

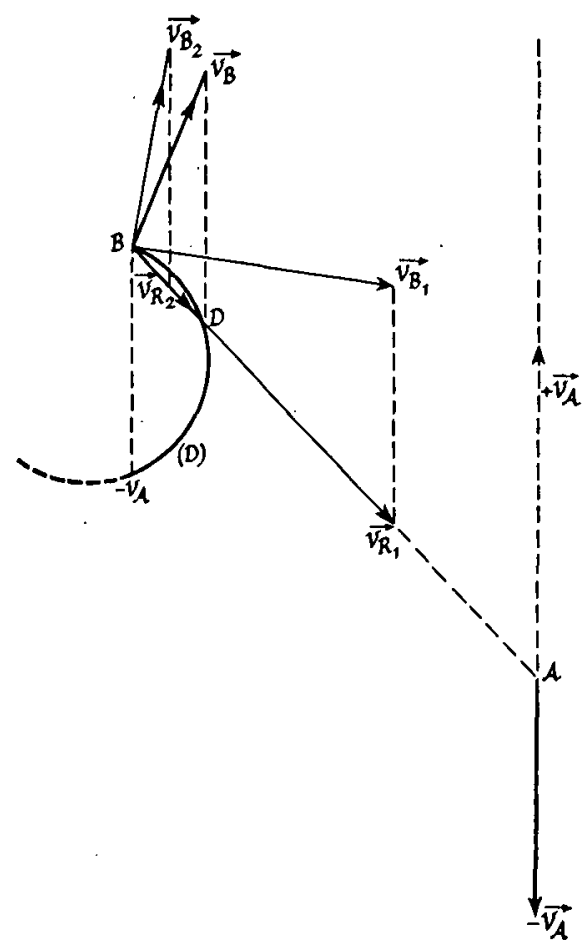

Fig. 2. Discriminating circle. 
For the limiting value $\mathrm{I}=5 \pi / 8$ (two points abaft the beam) the relative speed has this remarkable value:

$$
D=\frac{V_{N}}{\cos \frac{\pi}{8}} \cos \left(g+\frac{\pi}{8}\right)
$$

the equation for the circle, for which the ship's attitude is constant at $5 \pi / 8$. This circle, and the values of $D$, can be calculated in advance for the different bearings and for any given speed of the ship.

In consequence, a comparison of the relative speed (measured on the radar) with this discriminating value $D$, will tell us whether the ship is crossing or overtaking

$$
\begin{aligned}
& V_{R 1}>D=\text { crossing } \\
& V_{R 2}<D=\text { overtaking }
\end{aligned}
$$

Measuring $V_{R}$ is simply a matter of measuring a length on the screen, a simple procedure and one to which the instrument lends itself readily. Thus for the pair bearing-aspect (difficult to read on the radar) we substitute the pair bearingdistance (easy to read), and so we can extend to fog the Steering and Sailing Rules that hold good in clear weather: and then we are on familiar ground.

\title{
A Plotting Device for the Radar Observer
}

\author{
from Captain H. J. Sadler
}

To obtain all the available information from radar when visibility is poor, it is widely recognized that plotting is essential. No doubt plotting is carried out whenever possible, but in many merchant ships at sea today the ideal has limitations due to manning difficulties. Where the master has only one officer on the bridge to assist him it is not easy to cope with all bridge duties and carry out plotting in the usual way. To obtain full and accurate information a plotting officer must give his undivided attention to make use of the three known elements, range, bearing and own speed in order to produce the other ship's course, speed and nearest approach and follow up with the change of course and speed that may be required to keep out of the region of collision.

The plotting device depicted here is an attempt to give the radar observer an opportunity to plot the track of approaching ships himself without the use of instruments and without the assistance of a plotting officer. It may be of a convenient size, 14 in. $\times 8$ in., and backed by stiff cardboard so that it can be used without a table.

The principle of the diagram, Fig. I, is to expand the ship's position at the centre of the PPI to a base-line divided into angles on the bow and a perpendicular from the base-line indicating the range up to a convenient distance. The track of a ship's relative approach is plotted direct from the PPI and the diagram assists us to interpret the information that this track can give.

It can be seen that the constant bearing of another ship, when plotted, is a 